\title{
Importance of rheological heterogeneity for interpreting viscoelastic relaxation caused by the 2011 Tohoku-Oki earthquake
}

\author{
Hisashi Suito * (1)
}

\begin{abstract}
This study develops a three-dimensional viscoelastic model using the finite element method to understand the postseismic deformation that followed the 2011 Tohoku-Oki earthquake. The question of understanding which elements of the viscoelastic media affect the surface deformation is of particular importance. We first examined the individual effects of two different viscoelastic media, the mantle wedge and the oceanic mantle, which produce almost opposite deformation patterns. The mantle wedge controls eastward motion, uplift of the Pacific coastal and offshore regions, and extension across a broad area. In contrast, the oceanic mantle controls dominantly offshore westward motion, subsidence across a broad area, minor uplift of the surrounding areas, and contraction offshore. These differences are the most important issues for understanding the viscoelastic relaxation caused by subduction earthquakes. We then developed four different models to clarify which elements of the viscoelastic media affect the observed surface deformation. The simplest model, with uniform viscosity for all viscoelastic media, could explain the horizontal deformation but not the vertical deformation. The second model, with different viscosities for the mantle wedge and the oceanic mantle, could explain the onshore observations but could not explain the seafloor observations. The third model, which includes a thin weak layer beneath the subducting slab, could essentially explain the near-field onshore and seafloor observations but could not explain the far-field data. The final depth-dependent model was able to explain the far-field data as well as the near-field data. In these typical models, it is of particular importance to consider the different viscosities between the mantle wedge and the oceanic mantle and to include a thin weak layer beneath the slab, which has a dramatic impact on the seafloor deformation. Far-field data as well as near-field data are also important for constraining the viscoelastic structure; the former is sensitive to viscoelastic relaxation at greater depths. Clearly, viscoelastic relaxation alone cannot explain the observed deformation. A combined viscoelastic and afterslip model is necessary for constructing a complete postseismic deformation model.
\end{abstract}

Keywords: Viscoelastic relaxation, Postseismic deformation, The 2011 Tohoku-Oki earthquake, Rheological heterogeneity, FEM

\section{Background}

The $M_{w} 9.02011$ off the Pacific coast of Tohoku Earthquake (hereafter, the 2011 Tohoku-Oki earthquake) was the largest earthquake ever recorded in Japan and triggered substantial and long-lived postseismic deformation. The transient surface deformation that accompanies postseismic stress redistribution can provide new

\footnotetext{
*Correspondence: suito-h96qg@mlit.go.jp Geospatial Information Authority of Japan, Kitasato-1, Tsukuba, Ibaraki 305-0811, Japan
}

insights into the rheology and mechanics of the lithosphere and asthenosphere. Postseismic deformation is commonly observed following large earthquakes and is thought to be caused by three mechanisms: afterslip, viscoelastic relaxation, and poroelastic rebound. Shortterm deformation near the rupture zone is considered to be caused mainly by the afterslip mechanism or, at times, poroelastic rebound. It is commonly interpreted that the viscoelastic relaxation mechanism plays an important role only in long-term or far-field deformation. 
Viscoelastic relaxation and rheology estimated from analysis of geodetic data have been reported in studies of the postseismic deformation following inland earthquakes, such as the 1999 Izmit earthquake (Hearn et al. 2009), the 1999 Chi-Chi earthquake (Rousset et al. 2012), the 2002 Denali earthquake (Freed et al. 2006), and the 2004 Parkfield earthquake (Bruhat et al. 2011). In contrast, afterslip has been shown to be the dominant mechanism of postseismic deformation following major M7-M8 class subduction earthquakes, such as those occurring in the Japan Trench (Heki et al. 1997; Miyazaki et al. 2004), and in the Middle America and Peru-Chile Trenches (Graham et al. 2014; Remy et al. 2016). Combined afterslip and viscoelastic relaxation models were studied following M9 earthquakes that occurred in Chile (Hu et al. 2004), Alaska (Suito and Freymueller 2009), Sumatra (Broerse et al. 2015), and Maule (Klein et al. 2016).

Many researchers have studied the early postseismic deformation following the 2011 Tohoku-Oki earthquake. For example, Ozawa et al. (2012) argued that afterslip was the dominant mechanism; Diao et al. (2014) and Han et al. (2014) examined the combined effects of afterslip and viscoelastic relaxation; $\mathrm{Hu}$ et al. (2014) explored the effect of poroelastic rebound; and several authors showed that viscoelastic relaxation plays an important role even in short-term deformation (Sun et al. 2014; Sun and Wang 2015; Hu et al. 2016a). The most important results from these studies are those obtained using seafloor geodetic observation (SGO) (Watanabe et al. 2014; Tomita et al. 2015). In comparison with the onshore Global Navigation Satellite Systems (GNSS) sites, which move seaward in the same direction as the coseismic motion, the SGO sites move landward in the opposite direction. Sun et al. (2014) explained this landward deformation as an effect of viscoelastic relaxation, stressing that viscoelastic relaxation plays an important role even in short-term deformation. Subsequent studies have also identified viscoelastic relaxation as an important mechanism when interpreting postseismic deformation (e.g., Sun and Wang 2015; Yamagiwa et al. 2015; Hu et al. 2016a). However, despite the importance of viscoelastic relaxation, it is unclear which elements of the viscoelastic media affect the observed surface deformation.

In order to complement previous modeling efforts and to understand the postseismic deformation following the 2011 Tohoku-Oki earthquake, this study implements a three-dimensional viscoelastic model using the finite element method (FEM). The question of which elements of the viscoelastic media affect the surface deformation is of particular importance. The individual effects of two viscoelastic media, the mantle wedge and the oceanic mantle, are shown to contribute differently to the surface deformation. In addition, the deformation characteristics of viscoelastic relaxation based on four typical models are briefly summarized, and measurements of postseismic subsidence and landward motion on the seafloor are shown to be highly sensitive to viscoelastic structure, particularly to the inclusion of a thin weak layer beneath the subducting plate. Near-field data as well as far-field data, recorded $\sim 500 \mathrm{~km}$ from the rupture area, are both important for constraining viscoelastic structure. It should be noted that the purpose of this paper is not to construct a final postseismic deformation model; rather, the objective is to discuss the importance of rheological heterogeneity for interpreting postseismic deformation at subduction zones. Only the cumulative deformation is summarized; the temporal variation is not discussed in this paper.

\section{Characteristics of postseismic deformation}

Although abundant onshore GNSS data are available, only a very sparse GPS-acoustic dataset exists for the seafloor. Figure 1 shows the observed cumulative postseismic deformation for 5 years after the main shock at onshore sites and the cumulative deformation for almost 4 years at offshore sites, as reported by Watanabe et al. (2014) with modifications. It should be noted that the time period is different between the onshore and offshore data.

Onshore GNSS sites show deformation of up to approximately 120 and $50 \mathrm{~cm}$ in the horizontal and vertical directions, respectively, for 5 years after the main shock. It should be noted that coseismic offsets due to aftershocks are included at some sites. Each effect ranges between a few centimeters and several centimeters at the maximum, except for the 2011 Fukushima Hamadori and the 2014 Nagano-Hokubu earthquakes. All sites move approximately eastward (seaward) in the direction of the coseismic motion. The displacement direction is somewhat different in the southern part of the Kanto district, where the orientation is toward the SE, although eastward displacements are dominant in the surrounding areas.

Vertical deformation is more complex than horizontal deformation. The area of coseismic subsidence is now undergoing uplift, except in the northern part of the Tohoku district, with the largest uplift reaching $50 \mathrm{~cm}$ at the tip of the Oshika Peninsula. Inland and along the Japan Sea coast, the cumulative subsidence is up to $10 \mathrm{~cm}$, with significantly larger subsidence observed in the Ou Backbone area. In the northern part of the Tohoku district, the cumulative subsidence is approximately $5 \mathrm{~cm}$. However, uplift in this area began 1 year after the earthquake (Fig. 1c). A cumulative uplift of $\sim 10 \mathrm{~cm}$ is also observed in the Kanto, Chubu, and southern Hokkaido districts. It should be noted that uplift is 

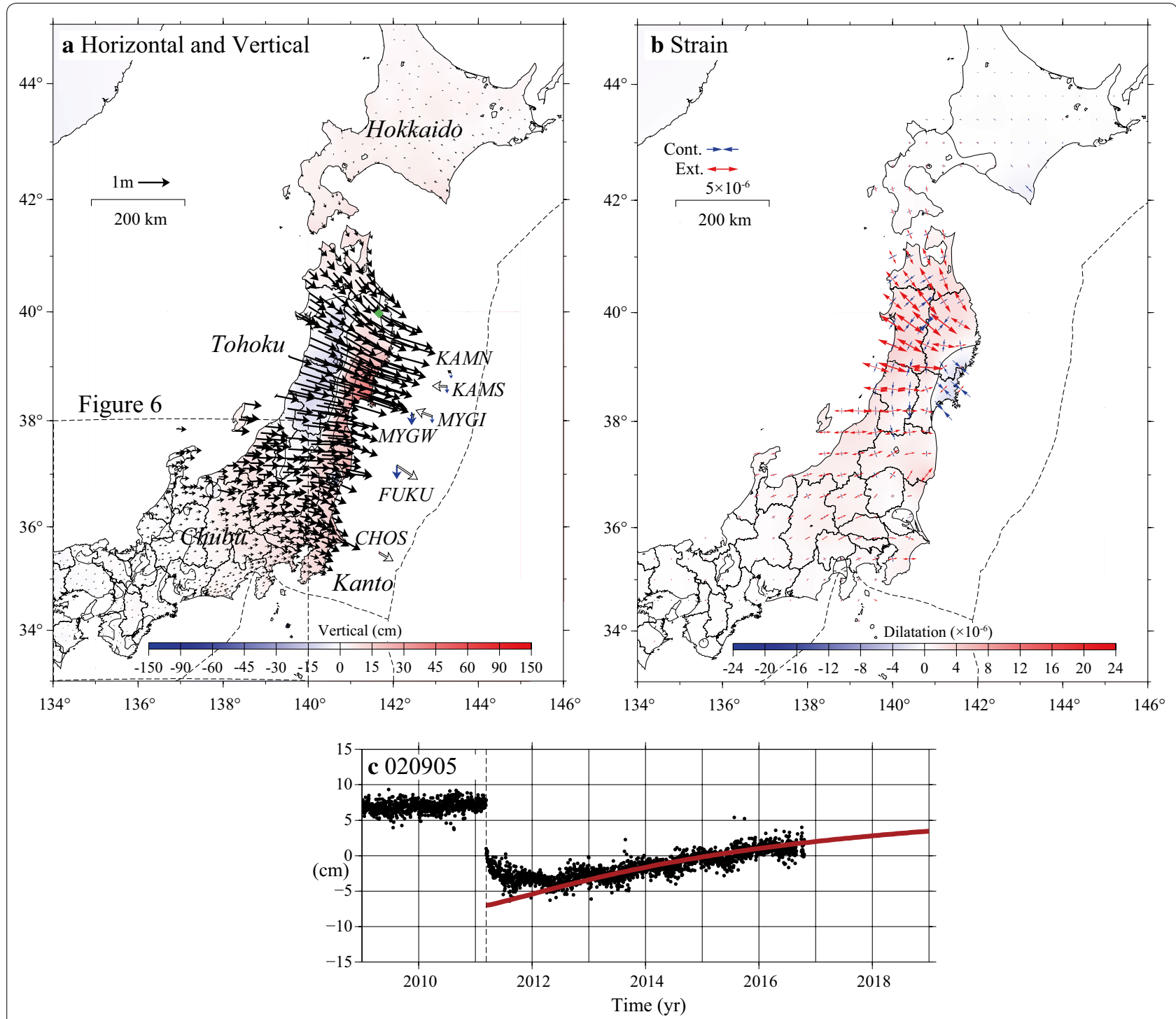

Fig. 1 Observed postseismic displacements and strain field, cumulative over 5 years. a Displacement field. Black arrows and contoured color map represent the 5-year cumulative horizontal and vertical displacements from onshore GNSS data, respectively. Open arrows and blue/red arrows represent 4-year cumulative horizontal and vertical displacements from offshore SGO data, respectively. The outlined area of Fig. 6 is also indicated by dashed lines. The green diamond denotes the GNSS site from which the time series displayed in (c) was obtained. The broken line denotes the plate boundary. b Principal strain axes and dilatational strain calculated from the horizontal displacements only, using the onshore GNSS data shown in (a). Arrows and contoured color map represent the 5-year cumulative principal strain axes and dilatational strain, respectively. c Time series of observed (black) and modeled (brown) vertical displacements at GNSS site (Iwaizumi3: 020905), the location of which is shown in (a)

also observed on Sado Island and in the north Tohoku district, although these regions are located on the Japan Sea coast.

The cumulative seafloor displacements used in this paper were compiled from Watanabe et al. (2014) with slight modifications. The displacement pattern is significantly different to the results obtained from onshore GNSS data, as mentioned previously. There is a strong along-trench gradient in amount and direction from nearly zero displacement at KAMN station, to tens of centimeters westward (landward) at KAMS and MYGI stations, and $50-70 \mathrm{~cm}$ eastward (seaward) at FUKU and CHOS stations. Although the MYGI station moves westward, the MYGW station, which is located $20 \mathrm{~km}$ west of MYGI, moves $20 \mathrm{~cm}$ in a SSE direction. All sites except for the FUKU and CHOS stations, which are located in the southern part of the focal area, moved in a different direction to the coseismic motion. In addition, 
all of the SGO sites, except for CHOS, revealed subsidence of approximately $20-50 \mathrm{~cm}$, whereas a large uplift is observed onshore along the Pacific coast.

Figure 1b shows the principal strain axes and dilatation for 5 years after the main shock. The strain calculation from the displacement vectors shown in Fig. 1a (onshore GNSS data only) is based on the method developed by Shen et al. (1996). Extensional strain is observed across the entire northeast Japan region, except for the area around the Oshika Peninsula on the Pacific coast, which is characterized by contractional strain. The dominant principal strain axes are E-W extension in the extensional area and E-W contraction in the contractional area. N-S contraction is also observed within the extensional area in the central part of the Tohoku district.

\section{FEM model description}

We used a FEM to compute both the coseismic displacements and the subsequent viscoelastic relaxations caused by the 2011 Tohoku-Oki earthquake, using the 3D FEM code GeoFEM developed by the Research Organization for Information Science and Technology (e.g., Iizuka et al. 2002; Okuda and Nakajima 2004). Figure 2 shows the $3 \mathrm{D}$ finite element meshes and the material properties assigned to each region. The model mesh is $2500 \mathrm{~km}$ long and $2800 \mathrm{~km}$ wide, and extends from the Earth's surface down to a depth of $700 \mathrm{~km}$, comprising 918,840 nodes and 888,552 elements. The optimized model used in this study consists of an elastic continental plate and subducting Pacific plate, in addition to a Maxwell linear viscoelastic mantle wedge, oceanic mantle, and thin weak layer (lithosphere-asthenosphere boundary: hereafter, LAB). Many recent viscoelastic models of the 2011 Tohoku-Oki

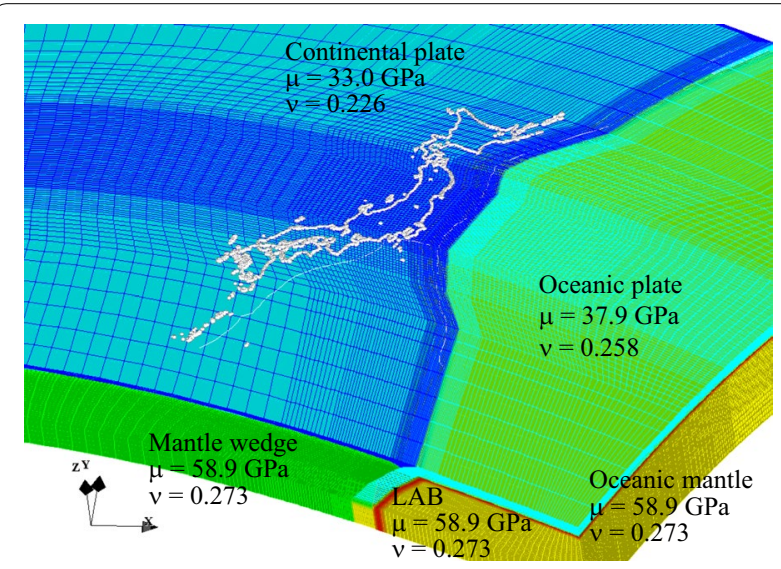

Fig. 2 Central part of the finite element mesh used in this study. Blue, aqua, green, yellow, and red colors represent the continental plate, oceanic plate, mantle wedge, oceanic mantle, and LAB, respectively. $\mu$ and $v$ are the rigidity and the Poisson's ratio, respectively earthquake used biviscous Burgers rheology (Sun et al. 2014; $\mathrm{Hu}$ et al. 2016a). Biviscous rheology can be fit to postseismic deformation that exhibits short-term transience followed by longer-term relaxation; therefore, this rheology is convenient for explaining the deformation rate change over time. However, the parameters involved are poorly known and are more complex than those used in Maxwell rheology. In addition, multiple relaxation times are explained by nonlinear stress-dependent rheology or by a combination of afterslip and viscoelastic relaxation that should be determined. In contrast, in Maxwell rheology, rock material exhibits instantaneous elastic behavior and longer-term viscous behavior. This rheology is very simple and is adequate for determining which elements of the viscoelastic media affect the cumulative surface deformation, which is the objective of this study. The thicknesses of the continental and subducting plates are assumed to be 30 and $80 \mathrm{~km}$, respectively. We constructed the geometry of the subducting plate interface referring to the combined plate interface depth contours of Nakajima and Hasegawa (2006), Nakajima et al. (2009), Uchida et al. (2009), and Kita et al. (2010). Taking the $X, Y$, and $Z$ coordinates as indicated in Fig. 2, we assumed that the model surface is a free surface and that the other five outer boundaries normal to the $X, Y$, or $Z$ axes can slip freely only in the $Y-Z, X-Z$, or $X-Y$ planes, respectively. We used the split node technique of Melosh and Raefsky (1981) to represent slipping faults within the model continuum.

\section{Results and discussion \\ Coseismic model}

Viscoelastic relaxation is dependent on the coseismic slip distribution. Therefore, this study refines previously published coseismic slip models to predict the viscoelastic relaxation with increased precision. The final coseismic model (Fig. 3) is not based on inversion. We perturbed the model to evaluate the effects of different assumptions on the viscoelastic relaxation predictions. We used forward modeling to identify the features of coseismic slip that are not well constrained and to determine the range of plausible models. Although we developed our model independently, the basic characteristics of the coseismic slip distribution in our final model strongly resemble those of published inversion models (e.g., Iinuma et al. 2012). For example, we similarly observe a very large slip $(>50 \mathrm{~m})$ near the trench, relatively small slip offshore of Fukushima and Ibaraki prefectures, and a slip area extending to a depth of $60 \mathrm{~km}$ offshore of Miyagi prefecture. It should be noted that an extremely large slip is observed along the shallow portion of the plate boundary offshore of Miyagi prefecture. This extremely large slip produces a large stress change in the oceanic mantle, which highlights the importance of the viscosity of the oceanic mantle and LAB. 


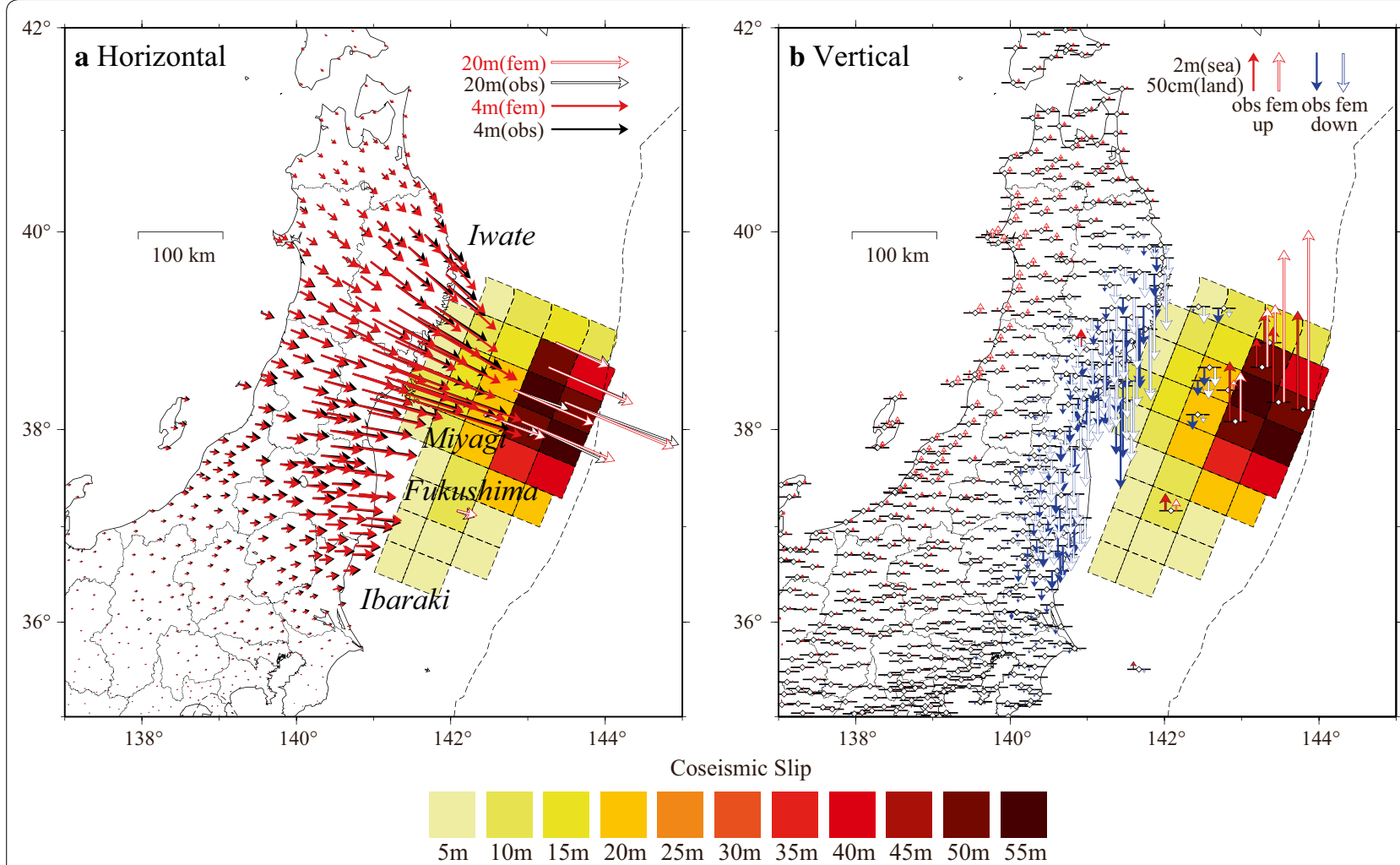

Fig. 3 Coseismic slip model and comparison of the observed and computed coseismic displacements. a Horizontal displacements. b Vertical displacements. The broken line denotes the plate boundary

\section{Viscoelastic relaxation of mantle wedge and oceanic mantle}

Given that the model geometry and the coseismic slip model are fixed, the main adjustable parameter in the viscoelastic model is the viscosity of the viscoelastic media. Our final model consists of three viscoelastic media-the mantle wedge, oceanic mantle, and LAB-which contribute differently to surface deformation. In this subsection, we first show the individual effects of relaxation in the mantle wedge and the oceanic mantle including the LAB (Fig. 4). The difference between the viscoelastic effect results from these two media is the most important issue for understanding viscoelastic relaxation following subduction earthquakes, as has already been partly reported by $\mathrm{Hu}$ et al. (2016a). We examined the individual effects by assuming viscoelasticity in only one medium; the other media are assumed to be elastic. The viscosity of the medium is assumed to be $2 \times 10^{18} \mathrm{~Pa} \mathrm{~s}$ in this trial. The amount of displacement depends on the viscosity; this fact is not important for the present trial, although the deformation pattern is essential.

Viscoelastic relaxation of the mantle wedge produces eastward (seaward) motion across the entire area, uplift of the onshore Pacific coastal region and offshore area, and minor subsidence of the Japan Sea coastal region (Fig. 4b). Extension across a broad area of northeast Japan and contraction across the onshore Pacific coastal region and the offshore area are also produced by the mantle wedge relaxation (Fig. 4c). The dominant principal strain axes are E-W extension in the Tohoku district and E-W contraction in the offshore area. N-S contraction is also produced in the central part of the Tohoku district.

In contrast, viscoelastic relaxation of the oceanic mantle produces an almost opposite deformation pattern to that of the mantle wedge, characterized by westward (landward) motion across the entire area, subsidence in the Tohoku district and offshore area, and uplift in the southern Hokkaido, Kanto, and Chubu districts and in the area beyond the trench (Fig. 4e). Contraction across the Tohoku district and offshore area, with minor extension across the surrounding area, and extension in the area beyond the trench are also produced by the oceanic mantle relaxation (Fig. 4f). The dominant principal strain axes are E-W contraction in the offshore area and in a limited area along the Pacific coast in the central Tohoku district. 


\section{a Mantle Wedge}
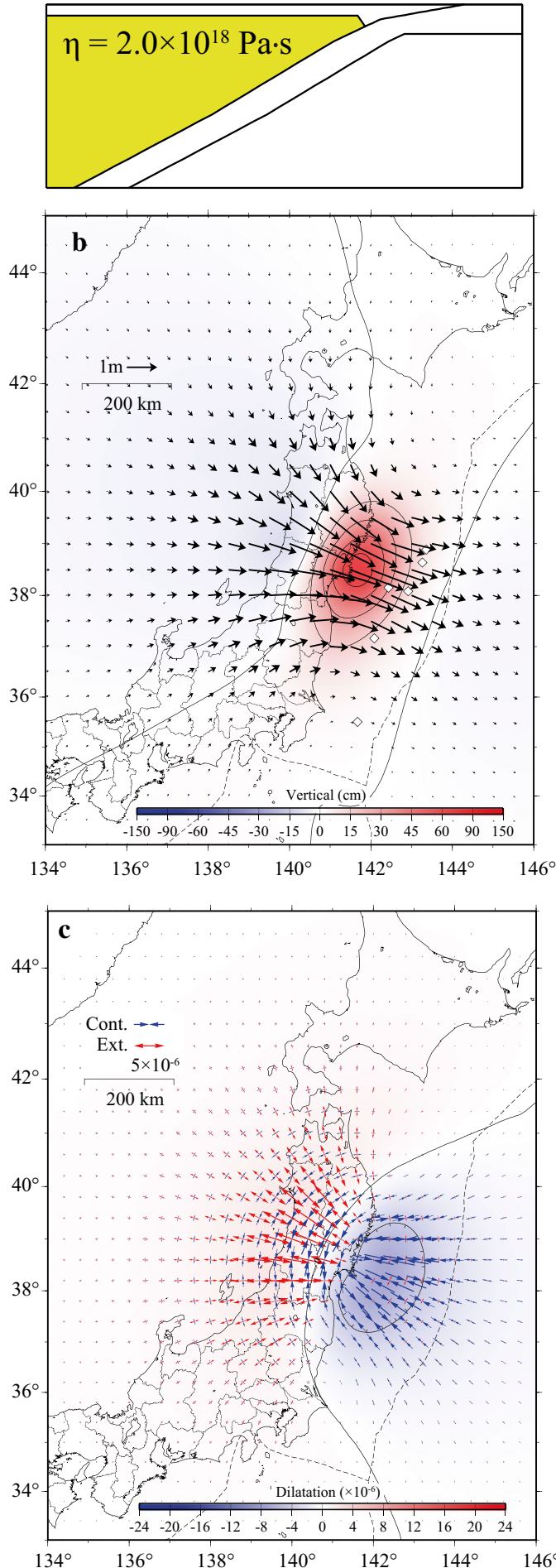

\section{d Oceanic Mantle}
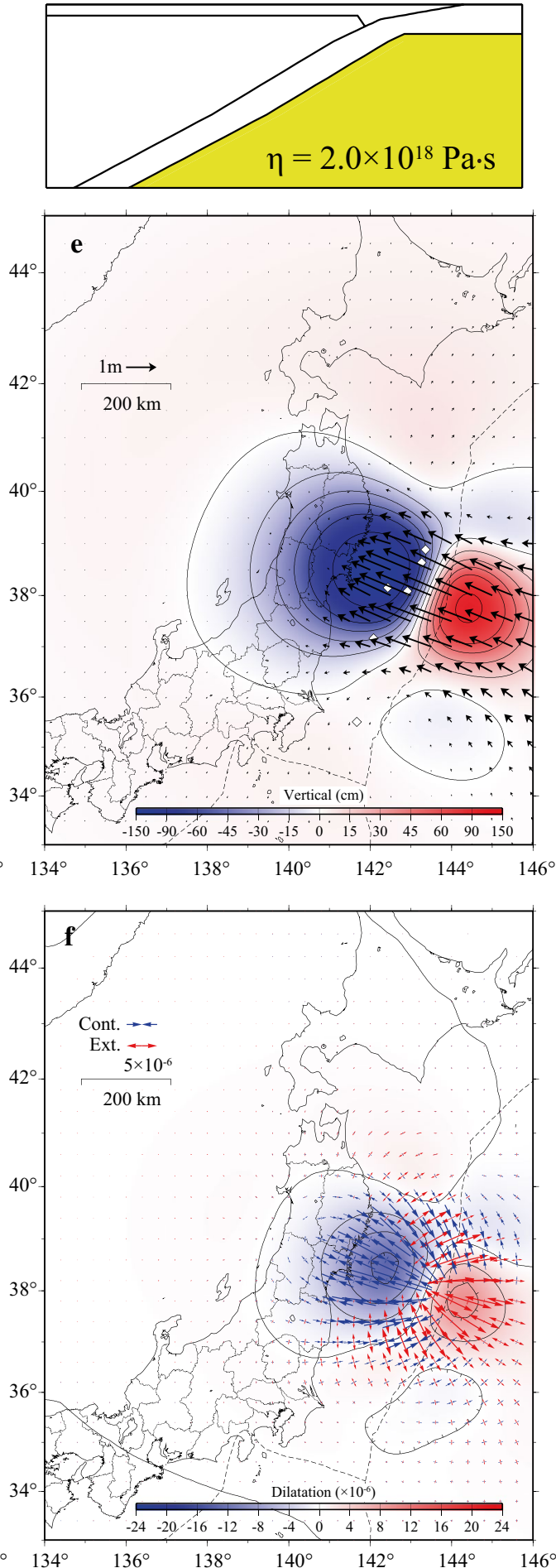

Fig. 4 Computed displacements and strain fields, cumulative for 5 years, due to viscoelastic relaxation. a-c Relaxation of the mantle wedge only. $\mathbf{d}-\mathbf{f}$ Relaxation of the oceanic mantle only. $\mathbf{a}$ and $\mathbf{d}$ Conceptual representations of the viscoelastic structure; the colored area represents the viscoelastic media. $\boldsymbol{\eta}$ is the viscosity. $\mathbf{b}$ and $\mathbf{e}$ Computed displacement field; black arrows and contoured color map represent horizontal and vertical displacements, respectively. $\mathbf{c}$ and $\mathbf{f}$ Computed strain field; arrows and contoured color map represent the principal strain axes and the dilatational strain, respectively 


\section{Viscoelastic relaxation according to four typical models}

We next summarize the basic characteristics of viscoelastic relaxation according to four typical models. These are Model 1, which has the same viscosity for all viscoelastic media; Model 2, with different viscosities for the mantle wedge and oceanic mantle; Model 3, with different viscosities for three viscoelastic media; and Model 4, in which viscosity is depth dependent (Fig. 5).

Assuming the same viscosity, $2 \times 10^{18} \mathrm{~Pa}$ s, for all viscoelastic media (Model 1), the mantle wedge and oceanic mantle relaxations affect the horizontal surface deformation equally (Fig. 5a), causing eastward motion onshore and westward motion on the seafloor (Fig. 4b, e). Regarding the vertical surface deformation, subsidence was dominant across the entire Tohoku district and was controlled mainly by relaxation in the oceanic mantle (Fig. 4e). This model can explain the observed horizontal deformation, although it cannot explain the vertical deformation characteristics. The main problem with this model is the assumption of the same viscosity for all viscoelastic media. Previous studies of viscoelastic relaxation at subduction zones have reported that the difference in viscosity between the mantle wedge and the oceanic mantle significantly affects the surface deformation (Hu et al. 2004; Wang 2007). In addition, these two media contribute differently to the surface deformation, as mentioned in the previous subsection. Moreover, DeMets et al. (2014) recently reported that the viscosity of the asthenosphere below the oceanic plate is greater than $1 \times 10^{19} \mathrm{~Pa}$ s. Since we considered that the viscosity of the oceanic mantle is higher than that of the mantle wedge, we used a viscosity value for the oceanic mantle of at least $1 \times 10^{19} \mathrm{~Pa}$ s. On the basis of Model 1 and the results of the previous studies, we next designed Model 2 , which assumes different viscosities between the mantle wedge, set at $2 \times 10^{18} \mathrm{~Pa} \mathrm{~s}$, and the oceanic mantle, set at $1 \times 10^{19} \mathrm{~Pa}$.

In the case of different viscosities between the mantle wedge and the oceanic mantle (Model 2), the mantle wedge relaxation dominates in both the horizontal and vertical displacements (Fig. 5b). This medium controls the dominantly onshore eastward motion and uplift of the Pacific coast and seafloor (Fig. 4b). This model can explain the onshore observations, but it fails to explain the seafloor observations, which is the most inadequate feature of the model. In order to address this problem, we incorporated a thin weak layer (LAB) below the subducting Pacific plate. The LAB is a mechanical decoupling of the oceanic lithosphere from the underlying mantle material, as reported in previous seismic velocity studies (e.g., Kawakatsu et al. 2009; Fischer et al. 2010). The origin of the LAB remains uncertain and may be due to the presence of either partial melt (Kawakatsu et al. 2009; Hirschmann 2010) or fluids (Karato and Jung 1998). A thin weak layer with low viscosity was introduced below the elastic plate to approximate this effect. Recent viscoelastic modeling studies have also incorporated this weak layer (Sun et al. 2014; Hu et al. 2016a). Our third tentative model consists of three viscoelastic media: the mantle wedge, with a viscosity of $2 \times 10^{18} \mathrm{~Pa} \mathrm{~s}$; the oceanic mantle, with a viscosity of $1 \times 10^{19} \mathrm{~Pa} \mathrm{~s}$; and the LAB, with a viscosity of $1 \times 10^{18} \mathrm{~Pa}$ s.

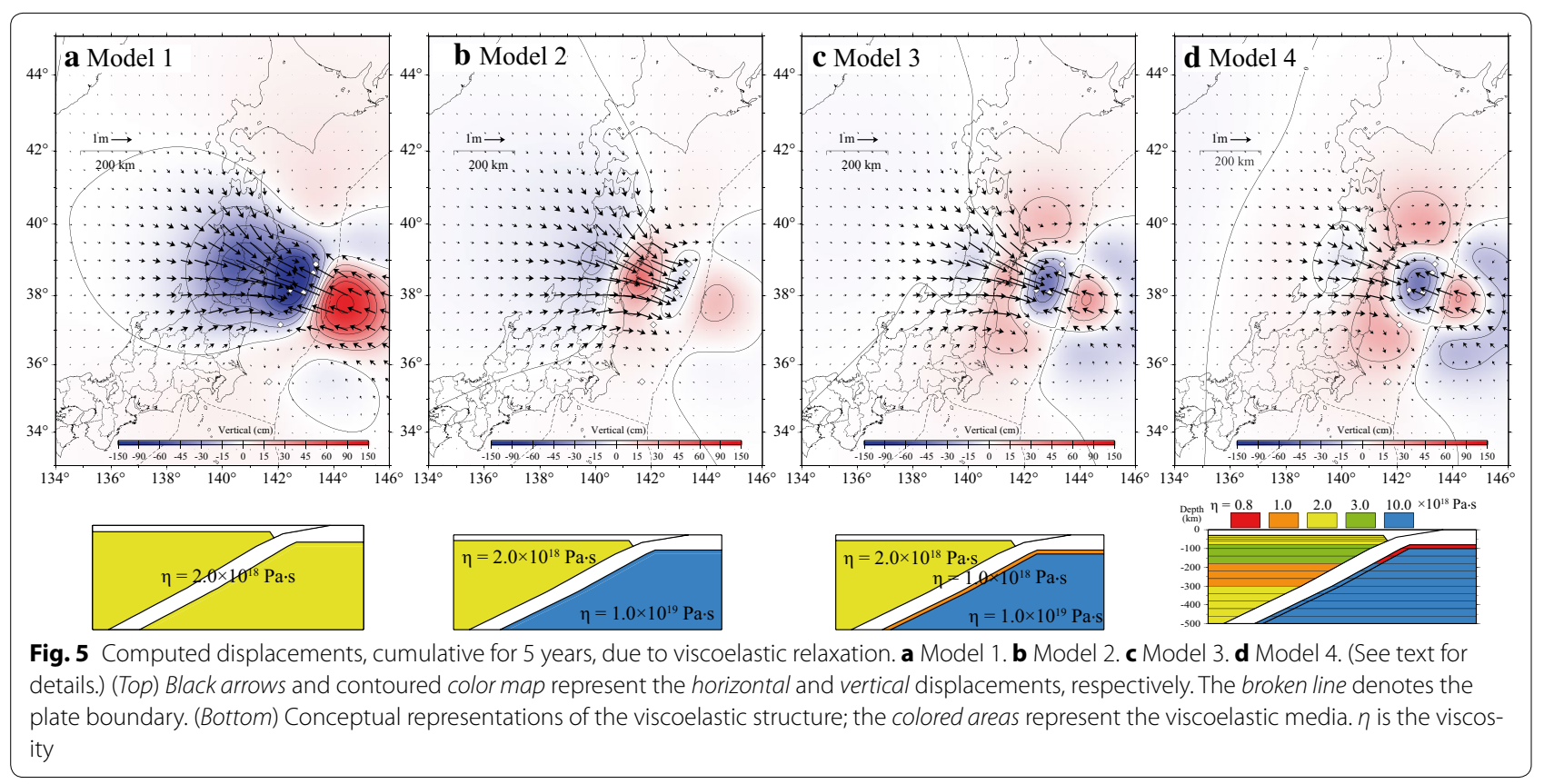


Using different viscosities for the three viscoelastic media somewhat improved the seafloor deformation in Model 3 (Fig. 5c). This model essentially explains the key observed characteristics, which are marked by eastward displacement onshore, westward displacement on the seafloor, subsidence of the seafloor and along the Japan Sea coast, and uplift along the Pacific coast and in the Kanto, Chubu, and southern Hokkaido districts (Fig. 1). This model can also explain the uplift on Sado Island and in the northern Tohoku district. However, although this model can explain the near-field observations fairly well, the far-field results were problematic. The horizontal displacement direction was somewhat different from that observed in the Chubu district, $\sim 500 \mathrm{~km}$ from the rupture area (Fig. 6a). In this area, the computed displacements were oriented in a NE direction, whereas the observed displacements are dominantly eastward. This difference may result from relaxation at a greater depth.

To complement the previous three models, we next considered the depth-dependent viscosity model. We conducted the computation using differential viscosities with a depth interval of $40 \mathrm{~km}$. The viscosities ranged from $1 \times 10^{18}-1 \times 10^{19} \mathrm{~Pa} \mathrm{~s}$ in the mantle wedge, $5 \times 10^{17}-1 \times 10^{19} \mathrm{~Pa} \mathrm{~s}$ for the LAB, and $1 \times 10^{19}-1 \times 10^{20} \mathrm{~Pa} s$ in the oceanic mantle. We then determined the optimum depth-dependent viscosity model (Model 4), which was constrained by the observed deformation characteristics summarized in "Characteristics of postseismic deformation" section. Of these, the key observations are the far-field displacement direction in the Chubu district, and the uplift on Sado Island and in the northern Tohoku district. Figure $5 \mathrm{~d}$ shows the results of Model 4. The general features are similar to Model 3; however, the horizontal displacement direction in the Chubu district was somewhat improved (Fig. 6a, b). We consider that this model best fits the observed data, reproducing the key characteristics of the cumulative 5 -year horizontal and vertical displacements and strain field (Fig. 1). In the following subsection, we compare this model to the data and discuss its varied results upon changing the viscosity, as well as the reasons for selecting Model 4 as the optimal model.

\section{Viscoelastic relaxation according to the optimal model}

Our viscoelastic model predicts eastward (seaward) motion in the onshore area, extending for the entire length of the earthquake rupture zone, whereas westward (landward) motion of the seafloor is limited to the large slip region (Fig. 7a). Overall, our viscoelastic-only model explained most of the horizontal deformation in the central Tohoku district, although some differences were noted in the northern and southern areas of the district. In these areas, and in the entire Kanto district, the degree of the predicted displacement was small compared to the observations. Therefore, large residuals of eastward displacement are concentrated in the northern and southern areas of the Tohoku and Kanto districts (Fig. 7c). Changing the viscosity can explain the residuals in these areas, although the predicted displacements were overestimated in the central Tohoku district. The spatial pattern of the predicted horizontal deformation did not change significantly as the viscosity was altered; only the magnitude of the deformation changed.
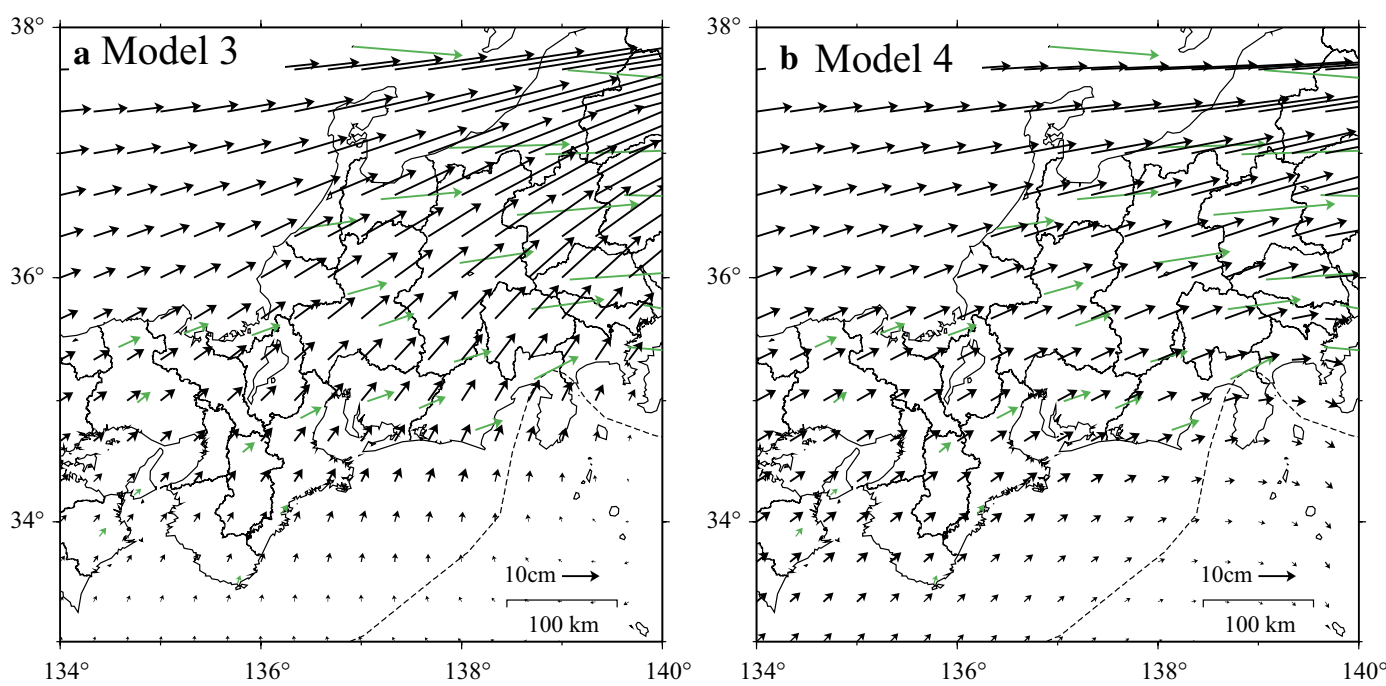

Fig. 6 Comparison of the computed and observed displacements, cumulative over 5 years. Black and green arrows indicate the computed and observed displacements, respectively. Observed displacements are displayed only for selected sites for clarity. a Model 3. b Model 4 

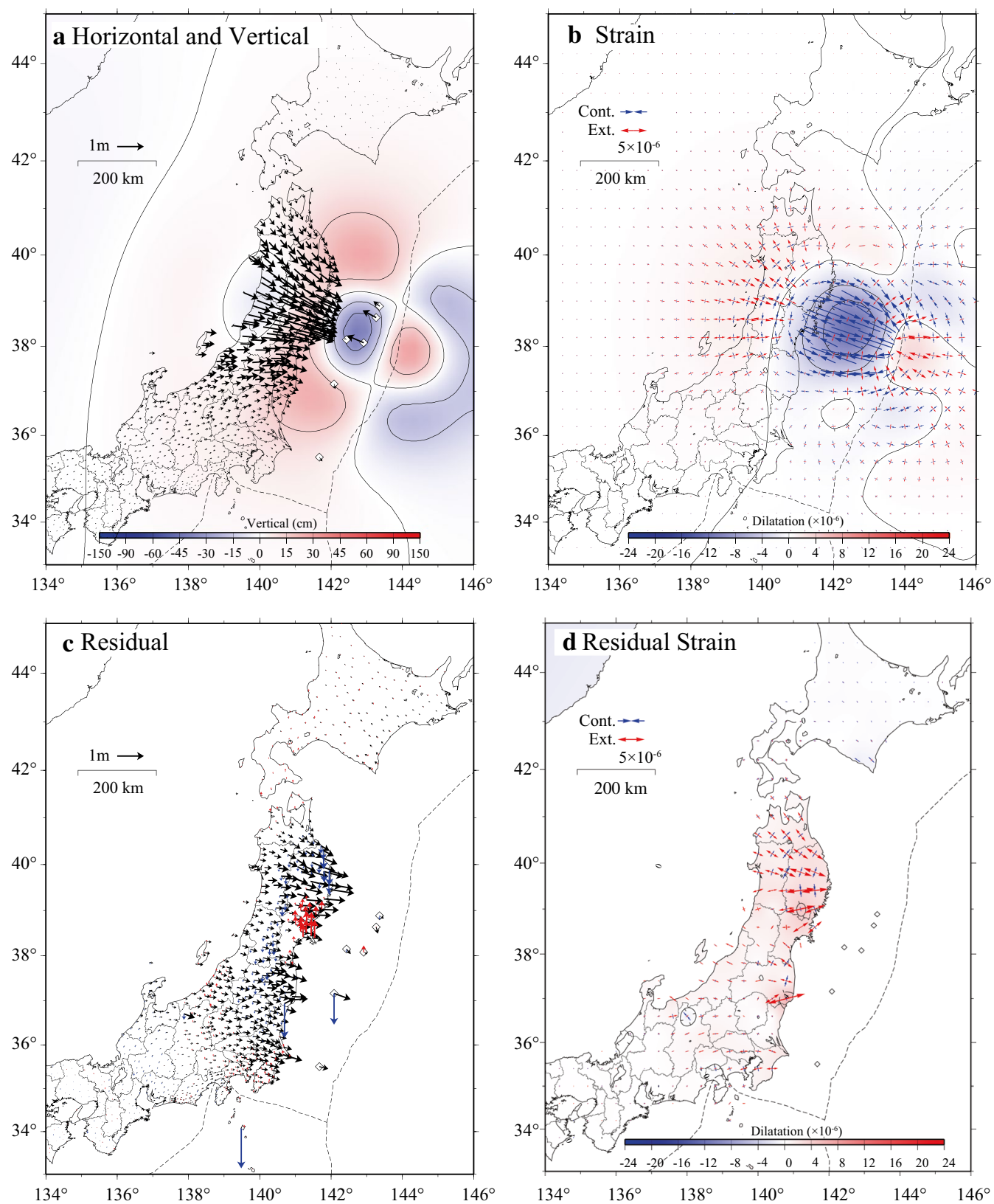

Fig. 7 Computed displacements (Model 4), cumulative over 5 years, due to viscoelastic relaxation and residual displacements. a Displacement field. Black arrows and contoured color map represent the horizontal and vertical displacements, respectively. The broken line denotes the plate boundary. b Strain field. Arrows and contoured color map represent the principal strain axes and dilatational strain, respectively. c Residual displacement field. Black and blue/red arrows represent the horizontal and vertical displacements, respectively. d Residual strain field. Arrows and contoured color map represent the principal strain axes and dilatational strain, respectively

Viscoelastic uplift was predicted over most of the coseismic subsidence area (Fig. 7a). The predicted area of subsidence is focused at the large slip zones on the seafloor and is also found in the Japan Sea coastal region. In northern Iwate prefecture, the predicted deformation resulting from viscoelastic relaxation alone is uplift, although the observed cumulative deformation is subsidence (Fig. 1a). Temporal variation occurs in this area. The area first subsided 1 year after the earthquake and subsequently began to uplift (Fig. 1c), as described in "Characteristics of postseismic deformation" section. Therefore, the uplift observed in this area is controlled by viscoelastic relaxation (Fig. 1c), whereas the subsidence first observed after 1 year was likely controlled by 
afterslip. It should be noted that the spatial pattern of the predicted vertical deformation is more sensitive than that of the horizontal deformation. In particular, the uplift or subsidence pattern in the Japan Sea coastal region and offshore area changed dramatically with viscosity. The predicted subsidence of the offshore area decreased as the viscosity of the oceanic mantle increased. In this case, the uplift on Sado Island and in the northern Tohoku district along the Japan Sea coast also decreased. In contrast, when the viscosity in the mantle wedge was reduced, the predicted subsidence in the offshore area increased, and the uplift along the Japan Sea coast also increased. Therefore, the ratio of the viscosity between the mantle wedge and the oceanic mantle has an important influence on the uplift and subsidence patterns.

Viscoelastic relaxation produces extension across the entire Tohoku district, except for the Pacific coastal region (Fig. 7b). Contraction is produced along the Pacific coast and offshore. The dominant principal strain axes are E-W extension in the extensional area and E-W contraction in the contractional area. N-S contraction is also produced within the extensional area in the central Tohoku district. The large area of extension is produced mainly by mantle wedge relaxation (Fig. 4c). In contrast, the area of contraction along the Pacific coast and offshore is produced by a combination of mantle wedge and oceanic mantle relaxation (Fig. 4c, f). The viscoelasticonly model generally explained the essential characteristics of the observed strain field. However, the extensional strain was somewhat small in the north Tohoku and Kanto districts; as similarly observed for the horizontal displacement field. Therefore, large residual extensional strain is concentrated in the northern and southern areas of the Tohoku and Kanto districts (Fig. 7d).

Clearly, viscoelastic relaxation alone cannot completely explain the observations, particularly in the northern and southern areas of the Tohoku and Kanto districts. The amounts of predicted displacement and extensional strain in these areas were small compared to the observations. Changing the viscosity can explain the residuals in these areas. In such a case, however, the predicted deformation is overestimated in other areas. Substantial viscoelastic flow was produced in the zones of high coseismic slip, which resulted in viscoelastic relaxation becoming the dominant mechanism in the neighboring areas. In contrast, viscoelastic relaxation was small in the zones of relatively low coseismic slip, which corresponds to the northern and southern Tohoku and Kanto districts. Afterslip is likely generated and plays an important role in this area.

\section{Assessment of viscoelastic structure}

The viscosity of the upper mantle wedge in northeast Japan was estimated from geodetic data obtained several years to decades after the occurrence of inland earthquakes such as the 1896 Riku-u earthquake (Suito and Hirahara 1999) and the 2008 Iwate-Miyagi Nairiku earthquake (Ohzono et al. 2012), as well as the 1993 Hokkaido-Nansei-Oki thrust earthquake on the eastern margin of the Japan Sea (Ueda et al. 2003). The postseismic signals following these events were explained using Maxwell rheology with a viscosity range of 2.4-9.3 $\times 10^{18}$ Pa s. Recent viscoelastic modeling studies of the 2011 Tohoku-Oki earthquake use Burgers rheology (Sun et al. 2014; Hu et al. 2016a); therefore, direct comparison may be difficult. The estimated viscosities of the Maxwell part are $1.8 \times 10^{18} \mathrm{~Pa} \mathrm{~s}$ (Sun et al. 2014) and $3 \times 10^{19} \mathrm{~Pa} \mathrm{~s}$ (Hu et al. 2016a). The mantle wedge viscosity of $2 \times 10^{18} \mathrm{~Pa} \mathrm{~s}$ in this study is consistent with these previous estimates, except for that of $\mathrm{Hu}$ et al. (2016a). However, a lower viscosity zone, with a viscosity of $1 \times 10^{18} \mathrm{~Pa} \mathrm{~s}$, is assumed at a depth of $25-100 \mathrm{~km}$ in the mantle wedge in the total effects model of $\mathrm{Hu}$ et al. (2016a). The viscosity of the oceanic mantle is generally found to be an order of magnitude higher than that of the mantle wedge (e.g., Hirth and Kohlstedt 2003). The oceanic mantle viscosity of $1 \times 10^{19} \mathrm{~Pa} \mathrm{~s}$ in this study, which is higher than that of the mantle wedge, is consistent with these rock rheological studies. We introduced a thin weak layer with low viscosity below the subducting plate to approximate the LAB. Hu et al. (2016a) suggested that the viscosity of this weak layer, at least $1 \times 10^{18} \mathrm{~Pa} \mathrm{~s}$, is sufficient to produce landward motion, although they assumed the thickness of the weak zone to be $80 \mathrm{~km}$. Our estimated viscosity is consistent with their results, although our model assumed the thickness of the weak layer to be $20 \mathrm{~km}$.

Depth-dependent viscosity typically originates from the temperature, pressure, and water content dependences of rock rheology (e.g., Hirth and Kohlstedt 2003). Considering this dependences, the minimum viscosity value may occur at a depth of around $100-200 \mathrm{~km}$ in the mantle wedge under hot and wet conditions (e.g., Karato and Jung 2003). The depth-dependent viscosity structure in this study contained the lowest viscosity at a depth of $150-300 \mathrm{~km}$, which is consistent with these rock rheological estimates. Although we also attempted to estimate the depth-dependent viscosity in the oceanic mantle, the depth dependence was not resolvable. Therefore, the optimum viscosity of $1 \times 10^{19} \mathrm{~Pa}$ s for the oceanic mantle was selected as the result. One of the best locations for studying oceanic mantle rheology is the Indian Ocean, where a large $M_{w} 8.6$ earthquake occurred in 2012 (e.g., Meng et al. 2012). Two recently published papers regarding oceanic mantle rheology analyze the postseismic deformation following the 2012 Indian Ocean earthquake (Hu et al. 2016b; Masuti et al. 2016). 
Small-scale rheological heterogeneities across the arc, such as a weak volcanic front and a strong forearc, contribute to local deformation, as reported by Muto et al. (2016); however, their modeling is based on a 2D profile. On close examination of the residuals of displacement in our model (Fig. 7c), the subsidence along the volcanic front in the central Tohoku district may reflect this effect. This type of small-scale heterogeneity should be incorporated into a more precise estimate of the viscoelastic effect in future modeling studies.

\section{Conclusions}

In order to complement previous modeling efforts and to understand the postseismic deformation following the 2011 Tohoku-Oki earthquake, we implemented a 3D viscoelastic model using FEM. The question of which elements of the viscoelastic media affect the surface deformation is of particular importance.

We first examined the individual effects of two viscoelastic media: the mantle wedge and the oceanic mantle including the LAB. These two media produced almost opposite deformation patterns. Mantle wedge relaxation controls dominantly onshore eastward (seaward) motion, uplift offshore and along the Pacific coast, and extension across a broad area. We noted that $\mathrm{N}-\mathrm{S}$ contraction observed in the central Tohoku district is produced only by mantle wedge relaxation. In contrast, oceanic mantle relaxation controls dominantly offshore westward (landward) motion, as well as subsidence across a broad area, minor uplift in the Kanto, Chubu, and Hokkaido districts, and contraction offshore and along the Pacific coast. The difference between the viscoelastic effects resulting from these two media is the most important issue for understanding viscoelastic relaxation caused by subduction earthquakes.

Next, we used four typical models to clarify which elements of the viscoelastic media affect the observed surface deformation. Of particular importance was the consideration of different viscosities between the mantle wedge and the oceanic mantle, and the inclusion of a thin weak layer (LAB), which has a dramatic impact on seafloor deformation. The simplest model, with uniform viscosity for all viscoelastic media (Model 1 ), was able to explain the observed horizontal deformation but not the vertical deformation. The second model, with different viscosities between the mantle wedge and oceanic mantle (Model 2), explained the observations onshore but not those on the seafloor. In order to improve the modeled seafloor deformation, we incorporated a thin weak layer (LAB) below the subducting Pacific plate. This third model, with different viscosities for the three viscoelastic media (Model 3), was able to essentially explain the important characteristics observed in the near-field data.
However, for the far-field data $(\sim 500 \mathrm{~km})$, the direction of the computed horizontal displacement was somewhat different from the observations. Finally, we developed a depth-dependent model, which explained the far-field data as well as the near-field data. This optimal model reproduced the horizontal displacement and strain field fairly well in the central part of the Tohoku district, and to some degree in the northern and southern areas of the district. Therefore, large residuals of eastward displacement are concentrated in these areas.

It is clear that viscoelastic relaxation alone cannot explain the observations. Substantial viscoelastic flow is produced in areas of very high coseismic slip. Therefore, viscoelastic relaxation plays an important role in neighboring areas, where it is the dominant deformation mechanism. In contrast, viscoelastic relaxation is minor in areas of relatively low coseismic slip. Afterslip is likely generated and plays an important role in these areas. In order to construct a complete postseismic deformation model of the 2011 Tohoku-Oki earthquake, it is necessary to estimate the afterslip distribution after removing the viscoelastic effect and to consider the temporal changes in the deformation in future studies.

\section{Abbreviations}

GNSS: Global Navigation Satellite System; SGO: seafloor geodetic observation; FEM: finite element method; LAB: lithosphere-asthenosphere boundary.

\section{Acknowledgements}

We used Generic Mapping Tools (Wessel and Smith 1998) to create the figures. Careful reviews and constructive comments from two reviewers, Dr. Jun Muto and Dr. Sylvain Barbot, were very helpful in revising the manuscript.

\section{Competing interests}

The author declares that he has no competing interests.

Received: 21 September 2016 Accepted: 24 January 2017

Published online: 31 January 2017

$$
\begin{aligned}
& \text { References } \\
& \text { Broerse T, Riva R, Simons W, Govers R, Vermeersen B (2015) Postseismic GRACE } \\
& \text { and GPS observations indicate a rheology contrast above and below the } \\
& \text { Sumatra slab. J Geophys Res 120:5343-5361. doi:10.1002/2015JB011951 } \\
& \text { Bruhat L, Barbot S, Avouac JP (2011) Evidence for postseismic deformation of } \\
& \text { the lower crust following the } 2004 \text { Mw. } 6.0 \text { Parkfield earthquake. J Geophys } \\
& \text { Res 116:B08401. doi:10.1029/2010JB008073 } \\
& \text { DeMets C, Marquez-Azua B, Cabral-Cano E (2014) A new GPS velocity field for } \\
& \text { the Pacific Plate-Part 1: constraints on plate motion, intraplate deforma- } \\
& \text { tion, and the viscosity of Pacific basin asthenosphere. Geophys J Int } \\
& \text { 199:1878-1899. doi:10.1093/gji/ggu341 } \\
& \text { Diao F, Xiong X, Wang R, Zheng Y, Walter TR, Weng H, Li J (2014) Overlapping } \\
& \text { post-seismic deformation processes: afterslip and viscoelastic relaxation } \\
& \text { following the 2011 M } 9.0 \text { Tohoku (Japan) earthquake. Geophys J Int } \\
& \text { 196:218-229. doi:10.1093/gji/ggt376 } \\
& \text { Fischer KM, Ford HA, Abt DL, Rychert CA (2010) The lithosphere-astheno- } \\
& \text { sphere boundary. Annu Rev Earth Planet Sci 38:551-575 } \\
& \text { Freed AM, Burgmann R, Calais E, Freymueller J (2006) Stress-dependent } \\
& \text { power-law flow in the upper mantle following the 2002 Denali, Alaska, } \\
& \text { earthquake. Earth Planet Sci Lett 252:481-489 }
\end{aligned}
$$


Graham SE, DeMets C, Cabral-Cano E, Kostoglodov V, Walpersdorf A, Cotte N, Brudzinski M, McCaffrey R, Salazar-Tlaczani L (2014) GPS constraints on the $\mathrm{M}_{\mathrm{w}}=7.5$ Ometepec earthquake sequence, southern Mexico: coseismic and post-seismic deformation. Geophys J Int 199:200-218. doi:10.1093/gji/ggu167

Han S, Sauber J, Pollitz FF (2014) Broadscale postseismic gravity change following the 2011 Tohoku-Oki earthquake and implication for deformation by viscoelastic relaxation and afterslip. Geophys Res Lett 41:5797-5805. doi:1 0.1002/2014GL060905

Hearn EH, McClusky S, Ergintav S, Reilinger RE (2009) Izmit earthquake postseismic deformation and dynamics of the North Anatolian Fault Zone. J Geophys Res 114:B08405. doi:10.1029/2008JB006026

Heki K, Miyazaki S, Tsuji H (1997) Silent fault slip following an interplate thrust earthquake at the Japan Trench. Nature 386:595-598

Hirschmann MM (2010) Partial melt in the oceanic low velocity zone. Phys Earth Planet Inter 179:60-71. doi:10.1016/j.pepi.2009.12.003

Hirth G, Kohlstedt DL (2003) Rheology of the upper mantle and the mantle wedge: a view from the experimentalists. In: Eiler J (ed) Inside the subduction factory, vol 138. AGU, Washington DC, pp 83-105 (Geophys Monogr)

Hu Y, Wang K, He J, Klotz J, Khazaradze G (2004) Three-dimensional viscoelastic finite element model for postseismic deformation of the great 1960 Chile earthquake. J Geophys Res 109:B12403. do::10.1029/2004JB003163

HuY, Burgmann R, Freymueller JT, Banerjee P, Wang K (2014) Contributions of poroelastic rebound and a weak volcanic arc to the postseismic deformation of the 2011 Tohoku earthquake. Earth Planet Space 66:106. doi:10.1186/1880-5981-66-106

Hu Y, Burgmann R, Uchida N, Banerjee P, Freymueller JT (2016a) Stress-driven relaxation of heterogeneous upper mantle and time-dependent afterslip following the 2011 Tohoku earthquake. J Geophys Res 121:385-411. doi:1 0.1002/2015JB012508

Hu Y, Burgmann R, Banerjee P, Feng L, Hill EM, Ito T, Tabei T, Wang K (2016b) Asthenosphere rheology inferred from observations of the 2012 Indian Ocean earthquake. Nature 538:368-372. doi:10.1038/nature19787

linuma T, Hino R, Kido M, Inazu D, Osada Y, Ito Y, Ohzono M, Tsushima H, Suzuki S, Fujimoto H, Miura S (2012) Coseismic slip distribution of the 2011 off the Pacific Coast of Tohoku Earthquake (M9.0) refined by means of seafloor geodetic data. J Geophys Res 117:B07409. doi:10.1029/201 2JB009186

lizuka M, Sekita D, Suito H, Hyodo M, Hirahara K, Place D, Mora P, Hazama O, Okuda H (2002) Parallel simulation system for earthquake generation: fault analysis modules and parallel coupling analysis. Concurr Comput: Pract Exper 14:499-519

Karato S, Jung H (1998) Water, partial melting and the origin of the seismic low velocity and high attenuation zone in the upper mantle. Earth Planet Sci Lett 157:193-207

Karato S, Jung H (2003) Effects of pressure on high-temperature dislocation creep in olivine. Phil Mag 83:401-414

Kawakatsu H, Kumar P, Takei Y, Shinohara M, Kanazawa T, Araki E, Suyehiro K (2009) Seismic evidence for sharp lithosphere-asthenosphere boundaries of oceanic plates. Science 324:499-502

Kita S, Okada T, Hasegawa A, Nakajima J, Matsuzawa T (2010) Anomalous deepening of a seismic belt in the upper-plane of the double seismic zone in the Pacific slab beneath the Hokkaido corner: possible evidence for thermal shielding caused by subducted forearc crust materials. Earth Planet Sci Lett 290:415-426

Klein E, Fleitout L, Vigny C, Garaud JD (2016) Afterslip and viscoelastic relaxation model inferred from the large-scale post-seismic deformation following the $2010 \mathrm{M}_{\mathrm{w}} 8.8$ Maule earthquake (Chile). Geophys J Int 205:1455-1472. doi:10.1093/gji/ggw086

Masuti S, Barbot SD, Karato S, Feng L, Banerjee P (2016) Upper-mantle water stratification inferred from observations of the 2012 Indian Ocean earthquake. Nature 538:373-377. doi:10.1038/nature19783

Melosh HJ, Raefsky A (1981) A simple and efficient method for introducing faults into finite element computations. Bull Seism Soc Am 71:1391-1400

Meng L, Ampuero JP, Stock J, Duputel Z, Luo Y, Tsai VC (2012) Earthquake in a maze: compressional rupture branching during the $2012 \mathrm{M}_{\mathrm{w}} 8.6$ Sumatra earthquake. Science 337:724-726. doi:10.1126/science.1224030

Miyazaki S, Segall P, Fukuda J, Kato T (2004) Space time distribution of afterslip following the 2003 Tokachi-oki earthquake: implications for variations in fault zone frictional properties. Geophys Res Lett 31:L06623. doi:10.1029/ 2003GL019410

Muto J, Shibazaki B, linuma T, Ito Y, Ohta Y, Miura S, Nakai Y (2016) Heterogeneous rheology controlled postseismic deformation of the 2011 Tohoku-Oki earthquake. Geophys Res Lett 43:4971-4978. doi:10.1002/2016GL068113

Nakajima J, Hasegawa A (2006) Anomalous low-velocity zone and linear alignment of seismicity along it in the subducted Pacific slab beneath Kanto, Japan: reactivation of subducted fracture zone? Geophys Res Lett 33:L16309. doi:10.1029/2006GL026773

Nakajima J, Hirose F, Hasegawa A (2009) Seismotectonics beneath the Tokyo metropolitan area, Japan: effect of slab-slab contact and overlap on seismicity. J Geophys Res 114:B08309. doi:10.1029/2008JB006101

Ohzono M, Ohta Y, linuma T, Miura S, Muto J (2012) Geodetic evidence of viscoelastic relaxation after the 2008 Iwate-Miyagi Nairiku earthquake. Earth Planet Space 64:759-764. doi:10.5047/eps.2012.04.001

Okuda H, Nakajima K (eds) (2004) Parallel Finite Element Analysis (I) Cluster Computing. Baifukan, Tokyo (in Japanese)

Ozawa S, Nishimura T, Munekane H, Suito H, Kobayashi T, Tobita M, Imakiire T (2012) Preceding, coseismic, and postseismic slips of the 2011 Tohoku earthquake, Japan. J Geophys Res 117:B07404. doi:10.1029/2011JB009120

Remy D, Perfettini H, Cotte N, Avouac JP, Chlieh M, Bondoux F, Sladen A, Tavera $\mathrm{H}$, Socquet A (2016) Postseismic relocking of the subduction megathrust following the 2007 Pisco, Peru, earthquake. J Geophys Res 121:39783995. doi:10.1002/2015JB012417

Rousset B, Barbot S, Avouac JP, Hsu YJ (2012) Postseismic deformation following the 1999 Chi-Chi earthquake, Taiwan: implication for lower-crust rheology. J Geophys Res 117:B12405. doi:10.1029/2012JB009571

Shen ZK, Jackson DD, Ge BX (1996) Crustal deformation across and beyond the Los Angeles basin from geodetic measurements. J Geophys Res 101:27957-27980. doi:10.1029/96JB02544

Suito H, Freymueller JT (2009) A viscoelastic and afterslip postseismic deformation model for the 1964 Alaska earthquake. J Geophys Res 114:B11404. doi:10.1029/2008JB005954

Suito H, Hirahara K (1999) Simulation of postseismic deformations caused by the 1896 Riku-u earthquake, northeast Japan: re-evaluation of the viscosity in the upper mantle. Geophys Res Lett 26:2561-2564

Sun T, Wang K (2015) Viscoelastic relaxation following subduction earthquakes and its effects on afterslip determination. J Geophys Res 120:1329-1344. doi:10.1002/2014JB011707

Sun T, Wang K, linuma T, Hino R, He J, Fujimoto H, Kido M, Osada Y, Miura S, Ohta Y, Hu Y (2014) Prevalence of viscoelastic relaxation after the 2011 Tohoku-oki earthquake. Nature 514:84-87. doi:10.1038/nature13778

Tomita F, Kido M, Osada Y, Hino R, Ohta Y, linuma T (2015) First measurement of the displacement rate of the Pacific Plate near the Japan Trench after the 2011 Tohoku-Oki earthquake using GPS/acoustic technique. Geophys Res Lett 42:8391-8397. doi:10.1002/2015GL065746

Uchida N, Nakajima J, Hasegawa A, Matsuzawa T (2009) What controls interplate coupling?: evidence for abrupt change in coupling across a border between two overlying plates in the NE Japan subduction zone. Earth Planet Sci Lett 283:111-121

Ueda H, Ohtake M, Sato H (2003) Postseismic crustal deformation following the 1993 Hokkaido Nansei-oki earthquake, northern Japan: evidence for a low-viscosity zone in the uppermost mantle. J Geophys Res 108:2151. doi:10.1029/2002JB002067

Wang K (2007) Elastic and viscoelastic models of crustal deformation in subduction earthquake cycles. In: Dixon TH, Moore JC (eds) The Seismogenic Zone of Subduction Thrust Faults. Columbia Univ Press, New York, pp $540-575$

Watanabe S, Sato M, Fujita M, Ishikawa T, Yokota Y, Ujihara N, Asada A (2014) Evidence of viscoelastic deformation following the 2011 Tohoku-Oki earthquake revealed from seafloor geodetic observation. Geophys Res Lett 41:5789-5796. doi:10.1002/2014GL061134

Wessel P, Smith WHF (1998) New, improved version of Generic Mapping Tools released. EOS Trans AGU 79:579. doi:10.1029/98ES00426

Yamagiwa S, Miyazaki S, Hirahara K, Fukahata Y (2015) Afterslip and viscoelastic relaxation following the 2011 Tohoku-oki earthquake $\left(M_{w} 9.0\right)$ inferred from inland GPS and seafloor GPS/Acoustic data. Geophys Res Lett 42:66-73. doi:10.1002/2014GL061735 